\title{
Validation of reference genes for RT-qPCR analysis of CYP4T expression in crucian carp
}

\author{
Fei Mo ${ }^{1}$, Jie Zhao ${ }^{1}$, Na Liu ${ }^{1}$, Li-hua Cao ${ }^{1,2}$ and Shan-xiang Jiang ${ }^{1}$ \\ ${ }^{1}$ Laboratory of Veterinary Pharmacology and Toxicology, College of Veterinary Medicine, \\ Nanjing Agricultural University, Nanjing, Jiangsu Province, China. \\ ${ }^{2}$ Guangdong Agribusiness Group Corporation, Guangzhou, Guangdong Province, China.
}

\begin{abstract}
Reference genes are commonly used for normalization of target gene expression during RT-qPCR analysis. However, no housekeeping genes or reference genes have been identified to be stable across different tissue types or under different experimental conditions. To identify the most suitable reference genes for RT-qPCR analysis of target gene expression in the hepatopancreas of crucian carp (Carassius auratus) under various conditions (sex, age, water temperature, and drug treatments), seven reference genes, including beta actin (ACTB), beta-2 microglobulin (B2M), embryonic elongation factor-1 alpha (EEF1A), glyceraldehyde phosphate dehydrogenase (GAPDH), alpha tubulin (TUBA), ribosomal protein 18 (RPL8) and glucose-6-phosphate dehydrogenase (G6PDH), were evaluated in this study. The stability and ranking of gene expression were analyzed using three different statistical programs: GeNorm, Normfinder and Bestkeeper. The expression errors associated with selection of the genes were assessed by the relative quantity of CYP4T. The results indicated that all the seven genes exhibited variability under the experimental conditions of this research, and the combination of ACTB/TUBA/EEF1A or of ACTB/EEF1A was the best candidate that raised the accuracy of quantitative analysis of gene expression. The findings highlighted the importance of validation of housekeeping genes for research on gene expression under different conditions of experiment and species.
\end{abstract}

Keywords: gene expression, quantitative RT-PCR, housekeeping genes, CYP4T, crucian carp.

Received: September 18, 2013; Accepted: January 24, 2014.

\section{Introduction}

Reverse transcription-quantitative PCR (RT-qPCR) is sensitive, specific and easy to operate, and is not only preferred in quantitative gene studies, but is also considered to be a "gold standard" for validating new techniques on gene expression (Mackay, 2004; Rajeevan et al., 2001; Fathallah-Shaykh, 2005; Park and Stegall, 2007). In order to improve the accuracy of RT-qPCR analysis, it is necessary to eliminate the variations in mRNA quality (Bustin, 2002; Imbeaud et al., 2005) and reverse transcription efficiency (Lekanne Deprez et al., 2002). Therefore, a normalization method is necessary to correct these errors. An internal reference gene or housekeeping gene is often used for this purpose. However, the expression of such genes frequently varies under different conditions, such as physiological state, tissue type, experimental treatments, and species differences (Ullmannova and Haskovec, 2003; Huggett et al., 2005; Ho-pun-Cheung et al., 2008; Infante et al., 2008; Chechi et al., 2012). Therefore, a stable refer-

Send correspondence to Shan-xiang Jiang. College of Veterinary Medicine, Nanjing Agricultural University, 210095 Nanjing, Jiangsu Province, China. E-mail: nauvy@sina.com. ence gene is to be identified and validated so as to improve the accuracy and reliability of RT-qPCR test.

Beta actin (ACTB) is a reference gene frequently used in fish (Jorgensen et al., 2006). Beta-2 microglobulin (B2MG), ribosomal protein 18 (RPL8), and embryonic elongation factor-1 alpha (EEF1A) have also been used as reference genes (Jorgensen et al., 2006; McCurley and Callard, 2008; Filby and Tyler, 2007; Julin et al., 2009) in other animals. Recently obtained data on fish species suggest, however, that these genes vary significantly with tissue types, life stages, or treatment paradigms (Filby and Tyler, 2007; Zhang and Hu, 2007; McCurley and Callard, 2008). To identify a relatively stable housekeeping gene, it is thus necessary to further test and compare these genes under different experimental conditions for mRNA analysis (Filby and Tyler, 2007; Tang et al., 2007; Small et al., 2008).

In this study, seven housekeeping genes which represented different functional classes and gene families, were used as candidates to normalize RT-qPCR data in crucian carp under different conditions (water temperature, age, sex and drug treatments). These are: ACTB, EEF1A, GAPDH, RPL8, TUBA (alpha tubulin), B2MG and G6PDH (glu- 
cose-6-phosphate dehydrogenase). Three software packages, GeNorm (Vandesompele et al., 2002), Bestkeeper (Pfaffl et al., 2004) and NormFinder (Andersen et al., 2004), were used to assess the stability of expression of the seven reference genes. CYP4T is a subfamily of the CYP450 superfamily involved in fatty acid metabolism and degradation of exogenous lipids (Hardwick, 2008). Studies on fish CYP4T are still rare to date, and only few published whole or partial CYP4T sequences are available for a small number of fish species. In this study, part of the crucian carp CYP4T sequence was amplified, and then CYP4T was used as a target gene to identify a stable reference gene for normalizing gene expression.

\section{Methods}

\section{Drugs}

Azithromycin (99\%) and Nicotinic Norfloxacin (98\%) were purchased from Zhejiang Guobang Pharmaceutical Co., Ltd. (Shangyu, Zhejiang, China), Ivermectin from Hebei Veyong Animal Pharmaceutical Co., Ltd. (96\%, Shijiazhuang, Hebei, China), Florfenicol from Zhejiang Runkang Pharmaceutical Co., Ltd. (98\%, Taizhou, Zhejiang, China), Hydrochloric Levamisole hydrochloride from Guilin Pharmaceutical Co., Ltd. (99\%, Guilin, Guangxi, China), Ceftriaxone from North China Pharmaceutical Co., Ltd. (98\%, Shijiazhuang, Hebei, China), and Rifampicin from Shijiazhuang Weierli Animals Pharmaceutical Co., Ltd. (99\%, Shijiazhuang, Hebei, China).

Lactobionic acid azithromycin, niconacid norfloxacin, levamisole hydrochloride and ceftriaxone sodium were dissolved in $0.9 \% \mathrm{NaCl}$ to $100 \mathrm{mg} / \mathrm{mL}, 100 \mathrm{mg} / \mathrm{mL}$, $40 \mathrm{mg} / \mathrm{mL}, \quad 50 \mathrm{mg} / \mathrm{mL}$, respectively. Ivermectin $(0.1 \mathrm{mg} / \mathrm{mL})$, florfenicol $(40 \mathrm{mg} / \mathrm{mL})$ and rifampicin $(160 \mathrm{mg} / \mathrm{mL})$ were dissolved in $0.9 \% \mathrm{NaCl}$. The three solutions contained $1 \%$ acetone, $5 \%$ polyethylene glycol 400 and $5 \%$ dimethyl sulfoxide, respectively.

\section{Fish and treatment}

Wild-type and cultured crucian carp, Carassius auratus, were obtained from Nanjing Fisheries Research Institute (Nanjing, Jiangsu, China). Forty crucian carp approximately one-year-old $(51 \pm 9.8 \mathrm{~g})$ and 40 approximately two-year-old $(123 \pm 16.9 \mathrm{~g})$ were divided into four groups (10 fish/group) each according to water temperature $\left(16^{\circ} \mathrm{C}\right.$ and $\left.26^{\circ} \mathrm{C}\right)$, and sex. Each group was maintained in a $60 \mathrm{~L}$ tank containing dechlorinated tap water with a constant photoperiod of $12 \mathrm{~h}$ light: $12 \mathrm{~h}$ darkness for 14 days. Subsequently, nine fish were randomly taken from each group. A hepatopancreas sample was excised from each fish, flash frozen in liquid nitrogen, and stored at $-80{ }^{\circ} \mathrm{C}$ until RNA extraction.

For experiments with different drugs, 80 adult ( $>$ two years post hatch) female crucian carp $(151 \pm 24.4 \mathrm{~g})$ were randomly divided into eight groups (10 fish/group) and maintained in a $60 \mathrm{~L}$ tank containing dechlorinated tap water with a constant photoperiod of $12 \mathrm{~h}$ light: $12 \mathrm{~h}$ darkness at $25 \pm 2{ }^{\circ} \mathrm{C}$ for 7 days prior to administration with different drugs for 7 days by intraperitoneal injection of lactobionic acid azithromycin $[50 \mathrm{mg} / \mathrm{kg}$ body weight $(\mathrm{BW})]$, ivermectin $(0.05 \mathrm{mg} / \mathrm{kg} \mathrm{BW})$, florfenicol (20 mg/kg BW), niconacid norfloxacin $(50 \mathrm{mg} / \mathrm{kg} \mathrm{BW})$, levamisole hydrochloride (20 mg/kg BW), ceftriaxone sodium ( $25 \mathrm{mg} / \mathrm{kg} \mathrm{BW})$, rifampicin $(80 \mathrm{mg} / \mathrm{kg} \mathrm{BW}$, as a positive control) and physiological saline $(0.5 \mathrm{~mL} / \mathrm{kg} \mathrm{BW}$, as a negative control). Other conditions of feeding management and the sampling methods were the same as described in the above paragraph. The protocol was approved by the Committee on the Ethics of Animal Experiments of Nanjing Agricultural University. The protocol was granted by the Science and Technology Agency of Jiangsu Province (approval ID: SYXK (SU) 2010-0005).

\section{RNA extraction and cDNA synthesis}

Total RNA was isolated from tissue samples using TransZol reagent (TransGen Biotech, Beijing, China), according to the manufacturer's instructions. Total RNA concentration and purity were analyzed in duplicate samples using a Nanodrop ND-2000 spectrophotometer (Thermo Fisher Scientific, MA, USA) for $A_{260} / A_{280}$ ratio verification , expected to range from 1.85 to 2.05 . RNA integrity was estimated by electrophoresis on $1.5 \%$ agarose gels and stained with Goldview. cDNA was synthesized from the qualified RNA using an RT-PCR reverse transcription kit (TransGen Biotech, Beijing, China). One $\mu$ g of total RNA was reverse transcribed into cDNA under the condition: $25{ }^{\circ} \mathrm{C}(10 \mathrm{~min}), 42{ }^{\circ} \mathrm{C}(30 \mathrm{~min} \mathrm{~s})$, and $85^{\circ} \mathrm{C}(5 \mathrm{~min})$, as manufacturer's recommendations. Then the cDNA was stored at $-20{ }^{\circ} \mathrm{C}$ until use.

\section{Primer design}

Seven reference genes were selected in this study: ACTB, B2M, EEF1A, GAPDH, TUBA, RPL8 and G6PDH. The TUBA, G6PDH and the target gene CYP4T primers were designed by optimizing and cloning the conserved sequences published in Genbank (Table 1). After amplifying the fragments and genomic sequencing, primers for the RT-qPCR assays were designed. Primer 5.0 (PREMIER Biosoft International, Palo Alto, CA, USA) was used in the design, and primers are listed in Table 2.

\section{Quantitative real-time PCR}

RT-qPCR assays were performed to evaluate gene expression profiles using an ABI PRISM ${ }^{\circledR} 7300$ Sequence Detection System. Each assay was done in a final volume of $10 \mu \mathrm{L}$, consisting of $5 \mu \mathrm{L} 2 \mathrm{x}$ SYBR Green Master Mix (TOYOBO, Shanghai, China), $1 \mu \mathrm{L}$ SYBR Green Plus buffer, $1 \mu \mathrm{L}$ diluted cDNA template, $400 \mathrm{nM}$ each primer, and nuclease free water. Samples were run in triplicate in 96 well plates with the following cycling parameters: $95^{\circ} \mathrm{C}$ 
Table 1 - Primers for PCR analysis.

\begin{tabular}{|c|c|c|c|}
\hline Gene & Accession No. & Primers $\left(5^{\prime} \rightarrow 3^{\prime}\right)$ & Amplicon size bp \\
\hline \multirow[t]{3}{*}{$T U B A$} & Danio rerio NM_194388 & & \\
\hline & Anoplopoma fimbria ВТ082446 & & \\
\hline & Salmo salar BT045702.1 & $\begin{array}{l}\text { F: CCTTCAACACCTTCTTCAGT } \\
\text { R:CAGAGGGAAGTGGATACGAG }\end{array}$ & 665 \\
\hline \multirow[t]{4}{*}{$G 6 P D H$} & Danio rerio XM_694076 & & \\
\hline & Oncorhynchus mykiss EF551311 & $\begin{array}{l}\text { F: TCARTGCATGAGCACCAAAG } \\
\text { R: GGACCACGRCTCCCGTATT }\end{array}$ & \\
\hline & Rhabdosargus sarba AY754640 & & \\
\hline & Oryzias latipes $\mathrm{AB} 111384$ & & 999 \\
\hline \multirow[t]{3}{*}{ CYP4T } & Danio rerio NM_199216 & & \\
\hline & Gobiocypris rarus EU593896 & $\begin{array}{l}\text { F: ACCTCCTGCACACTGGCTCTT } \\
\text { R: GTTCACCAGGTGGCAGAGGT }\end{array}$ & \\
\hline & Dicentrarchus labrax AF045468 & & 533 \\
\hline
\end{tabular}

${ }^{\mathrm{a}}: \mathrm{R}=\mathrm{A} / \mathrm{G}, \mathrm{M}=\mathrm{A} / \mathrm{C}, \mathrm{K}=\mathrm{G} / \mathrm{T}$.

for $60 \mathrm{~s}$, then 42 cycles of $95^{\circ} \mathrm{C}$ for $15 \mathrm{~s}, 62^{\circ} \mathrm{C}$ for $30 \mathrm{~s}$ and $72^{\circ} \mathrm{C}$ for $31 \mathrm{~s}$. Upon termination of the amplification phase, a dissociation step was performed at $95^{\circ} \mathrm{C}$ for $15 \mathrm{~s}, 60{ }^{\circ} \mathrm{C}$ for $1 \mathrm{~min}$ and $95^{\circ} \mathrm{C}$ for $15 \mathrm{~s}$ to check the purity of the amplification products. All samples displayed only a single peak, indicating a single pure product rather than primer dimers or non-specific PCR products. Controls without cDNA template were also used to determine the specificity of the amplification. A standardized four-fold dilution series (1/1 - 1/256) from pooled cDNA was used for calculation of the PCR efficiency for each gene, according to the equation $\mathrm{E} \%=\left(10^{-1 / \text { slope }}-1\right) \times 100$. The slope was calculated from a linear regression model against the $\mathrm{Ct}$ values of the serial dilutions of cDNA. All amplifications displayed PCR efficiencies between $95 \%$ and $115 \%$.

\section{Statistical analysis}

The stability and ranking of gene expression were evaluated using three different statistical programs: Bestkeeper GeNorm and Normfinder The relative quantity of gene expression was analyzed using an Excel spreadsheet. Significant differences between control and drug- treated groups were calculated using one-way ANOVA, followed by Least-significant difference (LSD) and Duncan's multiple range tests after checking the data normality and homogeneity of variances. $\mathrm{p}<0.05$ was considered to be significant.

\section{Results}

\section{Expression levels of the reference gene candidates}

The seven potential reference genes could be amplified in all individuals. The mean $\mathrm{Ct}$ values and standard errors are shown in Table 3 . The genes could be divided into two groups: a group of genes with a median $\mathrm{Ct}$ value below 23 (EEF1A, RPL8 and TUBA) or above 25 (B2MG, ACTB, G6PDH and GAPDH). Individual candidate reference genes showed similar expression, with differences in range from 1 to 2 among different sex, age and water temperature conditions. Nonetheless, across all studied samples, B2M showed the most unstable expression pattern, with $\mathrm{Ct}$ values differing by up to 6.61. GAPDH also showed high variability, with $\mathrm{Ct}$ values differing by 3.6.

Table 2 - Primers for RT-qPCR analysis.

\begin{tabular}{lcccc}
\hline Gene & Accession No. & Primers $\left(5^{\prime} \rightarrow 3^{\prime}\right)$ & Amplicon size bp \\
\hline ACTB & Carassius auratus AB039726 & F: ATGATGCCCCTCGTGCTGTT R: CCGTGCTCAATAGGATACTT & 151 \\
EEF1A & Carassius auratus AB056104 & F: ATGGGCTGGTTCAAGGGATG R:GACGGCTGGGTGGCAAAATG & 100 \\
RPL8 & Carassius auratus EU313780 & F: GCAGCAGAAGGCATCCACAC R: CTCCTCCAGACAGCAGACAAT & 123 \\
TUBA & Carassius auratus JX967535 & F: TGCCAACAACTACGCCCG R: AGAGGTGAAACCAGAGCC & 157 \\
B2MG & Carassius auratus AM690442 & F: CCAGTCCCAAGATTCAGG R: ATGGCAGATTAGGGTGTT & 71 \\
G6PDH & Carassius auratus JX967536 & F: AGAGGAAGGCAGAGGTGAGG R: TTCGTAGGCATCGGGCAG & 224 \\
GAPDH & Carassius auratus AM701793 & F: ACTGGTATGGCATTCCGTGT R: GTCCTTGATGTCAGCGTAGC & 97 \\
CYP4T & Carassius auratus JX412927 & F: TTTGAACATCCACCACCCAT R: AAGTAAGCCATCGCCTAACC & 105 &
\end{tabular}


Table 3 - Average Ct values \pm SD of the seven reference genes in the different experimental setups.

\begin{tabular}{|c|c|c|c|c|c|c|c|c|}
\hline Treatment & EEF1A & RPL8 & TUBA & B2MG & ACTB & G6PDH & GAPDH & \\
\hline \multirow[t]{8}{*}{ Drug } & Azithromycin & $20.49 \pm 0.78$ & $20.86 \pm 0.59$ & $23.90 \pm 0.37$ & $29.78 \pm 1.84$ & $27.22 \pm 0.43$ & $25.87 \pm 0.32$ & $27.97 \pm 0.52$ \\
\hline & Ivermectin & $20.88 \pm 0.66$ & $21.05 \pm 0.93$ & $24.34 \pm 1.58$ & $29.23 \pm 0.45$ & $27.53 \pm 1.10$ & $27.21 \pm 0.12$ & $29.13 \pm 0.99$ \\
\hline & Florfenicol & $19.86 \pm 0.19$ & $20.57 \pm 0.50$ & $23.87 \pm 0.37$ & $29.19 \pm 1.05$ & $27.22 \pm 0.15$ & $26.91 \pm 0.52$ & $28.54 \pm 0.35$ \\
\hline & Norfloxacin & $19.40 \pm 0.51$ & $19.28 \pm 0.58$ & $22.23 \pm 0.46$ & $26.52 \pm 0.98$ & $25.80 \pm 0.46$ & $24.91 \pm 0.55$ & $26.21 \pm 0.69$ \\
\hline & Levamisole & $18.73 \pm 0.57$ & $18.63 \pm 0.53$ & $21.97 \pm 0.24$ & $25.12 \pm 0.41$ & $25.46 \pm 0.56$ & $25.52 \pm 0.90$ & $26.28 \pm 1.02$ \\
\hline & Ceftriaxone & $18.73 \pm 0.13$ & $18.68 \pm 0.17$ & $21.38 \pm 0.23$ & $25.36 \pm 0.92$ & $24.72 \pm 0.11$ & $25.15 \pm 0.15$ & $25.53 \pm 0.39$ \\
\hline & Rifampicin & $18.71 \pm 0.55$ & $18.65 \pm 0.59$ & $21.49 \pm 0.48$ & $26.83 \pm 1.02$ & $25.11 \pm 0.61$ & $25.41 \pm 0.69$ & $25.95 \pm 0.75$ \\
\hline & Control & $18.59 \pm 0.74$ & $18.57 \pm 0.62$ & $22.24 \pm 0.86$ & $27.90 \pm 1.25$ & $25.79 \pm 0.77$ & $26.45 \pm 0.48$ & $27.06 \pm 1.18$ \\
\hline \multirow[t]{4}{*}{16} & One-year-old male & $19.29 \pm 0.39$ & $19.99 \pm 0.22$ & $21.94 \pm 0.44$ & $23.61 \pm 0.80$ & $25.47 \pm 0.43$ & $25.09 \pm 0.72$ & $27.04 \pm 1.64$ \\
\hline & Two-year-old male & $20.25 \pm 0.04$ & $21.10 \pm 0.04$ & $22.71 \pm 0.06$ & $24.54 \pm 0.91$ & $26.44 \pm 0.22$ & $26.96 \pm 0.30$ & $28.09 \pm 0.97$ \\
\hline & One-year-old female & $19.79 \pm 0.61$ & $20.14 \pm 0.92$ & $22.50 \pm 0.59$ & $23.53 \pm 0.62$ & $25.60 \pm 0.40$ & $26.21 \pm 1.21$ & $26.93 \pm 1.37$ \\
\hline & Two-year-old female & $19.75 \pm 0.69$ & $20.07 \pm 1.00$ & $22.53 \pm 0.73$ & $23.57 \pm 0.94$ & $25.90 \pm 0.65$ & $26.02 \pm 0.54$ & $27.42 \pm 0.53$ \\
\hline \multirow[t]{6}{*}{26} & One-year-old male & $18.81 \pm 0.31$ & $19.59 \pm 0.37$ & $22.34 \pm 0.52$ & $23.24 \pm 0.59$ & $25.62 \pm 0.55$ & $26.41 \pm 1.00$ & $27.32 \pm 1.31$ \\
\hline & Two-year-old male & $19.73 \pm 0.40$ & $20.26 \pm 0.63$ & $23.33 \pm 0.83$ & $23.64 \pm 0.49$ & $26.73 \pm 1.22$ & $27.03 \pm 1.13$ & $27.69 \pm 1.10$ \\
\hline & One-year-old female & $18.87 \pm 0.34$ & $19.48 \pm 0.49$ & $22.79 \pm 0.79$ & $23.17 \pm 0.12$ & $26.03 \pm 0.53$ & $26.43 \pm 0.95$ & $27.37 \pm 1.11$ \\
\hline & Two-year-old female & $19.37 \pm 0.06$ & $19.96 \pm 0.15$ & $23.36 \pm 0.18$ & $23.86 \pm 0.88$ & $26.59 \pm 0.32$ & $26.27 \pm 0.42$ & $28.15 \pm 0.34$ \\
\hline & maximum & $20.88 \pm 0.66$ & $21.10 \pm 0.04$ & $24.34 \pm 1.58$ & $29.78 \pm 1.84$ & $27.53 \pm 1.10$ & $27.21 \pm 0.12$ & $29.13 \pm 0.99$ \\
\hline & minimun & $18.59 \pm 0.74$ & $18.57 \pm 0.62$ & $21.38 \pm 0.23$ & $23.17 \pm 0.12$ & $24.72 \pm 0.11$ & $24.91 \pm 0.55$ & $25.53 \pm 0.39$ \\
\hline
\end{tabular}

The variability for the other reference genes was between 2 and 3.

\section{Stability analysis by GeNorm}

In GeNorm, paired difference analysis of normalization factors is used to determine the optimal number of necessary housekeeping genes (Vandesompele et al., 2002). In this program, genes are ranked according to their transcript stability values $M$ via pairwise comparison. The gene with the lowest $M$ value possesses the most stable transcription. If $M$ is greater than 1.5 , the corresponding gene should be removed from the set. The optimal number of reference genes for normalization is chosen by pairwise variation $\left(V_{n / n+1}\right)$ analysis. If the value is below 0.15 , addition of another reference gene is not required. In this way, GeNorm assesses the stability of the best pair of reference genes but not the stability of a single gene. In the present study, the results of the ranking of the seven examined genes by GeNorm under different conditions (Figure 1) indicated that ACTB and TUBA were the most stably expressed pair of reference genes, followed by EEF1A and RPL8. The results of the $\mathrm{V}_{n / n+1}$ analysis (Figure 2) indicated that inclusion of a third reference gene was required for different physiological, environmental and drug factors in crucian carp.

\section{Stability analysis by NormFinder}

NormFinder is a Microsoft ${ }^{\circledR}$ Excel add-in (Andersen et al., 2004). The operating principle of the program is simi- lar to that of GeNorm. However, NormFinder produces a direct estimation of expression variation, and a lower stability value implies an increased stability of gene expression. Based on the intra- and inter-group variations of each gene, this program determines automatically the most stably expressed candidate reference gene and gene-pair. Table 4 shows the intra-group stability values of the candidates. EEF1A and ACTB were identified as the most stable pair of the candidate reference genes and ACTB as the most stable single gene.

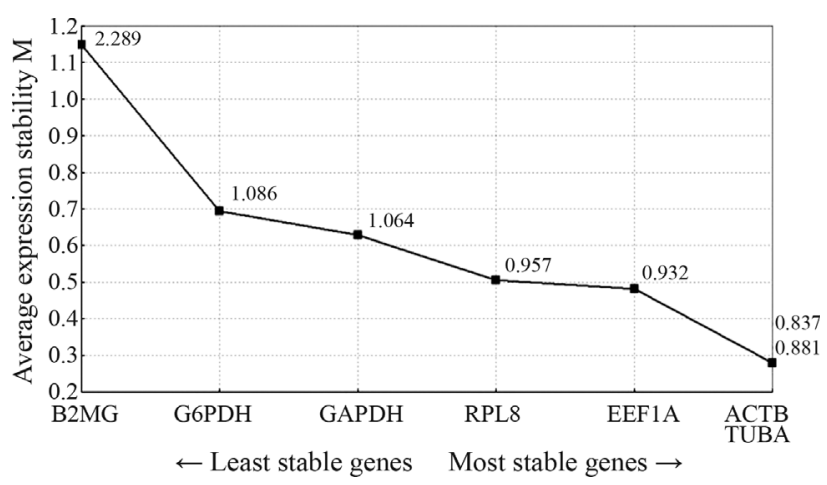

Figure 1 - Average values $(M)$ of expression stability of reference genes analyzed by the GeNorm program. This graph displays the output of GeNorm plotting the $M$ value against the reference genes within every sampling from each group. 


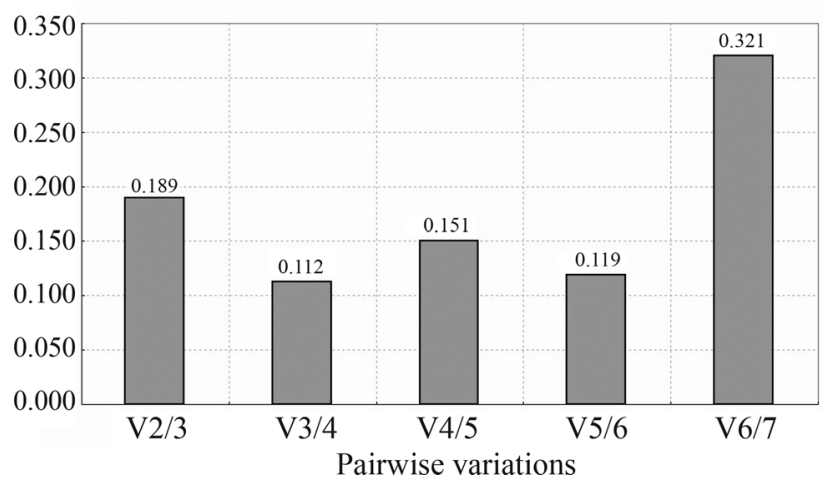

Figure 2 - Determination of the optimal number of reference genes for normalization. The program calculates the $V_{n / n+1}$ between two sequential normalization factors. Using the cut-off value $V=0.15$, three genes were required for accurate normalization under this condition. The three reference genes were ACTB, TUBA and EEF1A.

\section{Stability analysis by BestKeeper}

BestKeeper software analyzes a maximum of ten housekeeping genes and ten target genes separately, which is mainly dependent on the pairwise co-efficient of correlation and the BestKeeper index (the geometric mean of $\mathrm{Ct}$ value of each candidate gene) (Pfaffl et al., 2002). A gene with a higher coefficient of correlation means that its expression correlates well with the expression patterns of the other reference genes. Moreover, high percentage covariance $(\mathrm{CP})$ and standard deviation $(\mathrm{SD})$ mean low stability of expression of the samples, and the gene with a SD higher than one can be considered to be expressed inconsistently across the samples.

The results shown in Table 5 indicated that, compared to the other reference genes, the $\mathrm{SD}$ and $\mathrm{CP}$ variation of GAPDH and B2MG were high, which was a reason to exclude them from index calculation. G6PDH with a low correlation co-efficient (0.758) could also be excluded. After removal of GAPDH, B2MG and G6PDH, the significance and the correlation between the remaining reference genes increased $(0.956<\mathrm{r}<0.985)$ (only rounded data are shown). This suggested that the expression of ACTB, EEF1A, RPL8 and TUBA were stable in fish hepatopancreas under different conditions (water temperature, sex, age, and drug treatments). Moreover, ACTB and TUBA

Table 4 - The stability of reference genes measured by Normfinder.

\begin{tabular}{lc}
\hline Reference gene & Stability value \\
\hline RPL8 & 0.010 \\
EEF1A & 0.007 \\
$A C T B$ & 0.005 \\
GAPDH & 0.008 \\
TUBA & 0.006 \\
G6PDH & 0.010 \\
$B 2 M G$ & 0.023 \\
\hline
\end{tabular}

Table 5 - The stability of reference genes tested by Bestkeeper.

\begin{tabular}{lc}
\hline Reference gene & Co-efficient of correlation \\
\hline$A C T B$ & 0.864 \\
GAPDH & 0.684 \\
EEF1A & 0.893 \\
$R P L 8$ & 0.850 \\
$B 2 M G$ & 0.747 \\
$T U B A$ & 0.861 \\
G6PDH & 0.491 \\
\hline
\end{tabular}

possessed the best stability with the highest correlation co-efficient and the lowest SD/CP.

\section{Effects of reference genes on CYP4T relative gene expression}

In order to detect the reliability of the analyzed results of the three software programs, the housekeeping genes (ACTB, EEF1A, GAPDH, RPL8, TUBA, B2MG and G6PDH), individually and in pairs, were used respectively as internal reference to calculate the relative expression of the target gene CYP4T in crucian carp.

Discrepancies were observed when using different reference genes to normalize qPCR data. As shown in Figure 3, when the expression levels were normalized to different housekeeping genes, CYP4T showed some significant differences in two-year-old fish across different temperature and sex $(p<0.05)$. The results showed that the expression of CYP4T in two-year-old male fish was higher than in females. Especially at $26{ }^{\circ} \mathrm{C}$ (Figure 3a), when the data were nomalized to different reference genes and gene combinations, some samples would exhibit significant differences (TUBA, EEF1A, RPL8, G6PDH, and ACTB / EEF1A, ACTB / EEF1A / TUBA).

Differences were also observed in the ratio of the two groups (1.53- to 3.85-fold). Likewise, the influences of temperature on male and female crucian carp were different. The expression of CYP4T was higher in two-year-old female fish breeding at $16^{\circ} \mathrm{C}$ than at $26^{\circ} \mathrm{C}(1.11$ - to 2.61 fold). Significant differences were observed when EEF1A, RPL8 or ACTB/EEF1A were used for normalization (Figure $3 b$ ). In two-year-old males, no significant effect was apparent on the relative gene expression of CYP4T at different temperatures, except when TUBA was used for normalization (Figure 3c). However, this was quite different when the estimate of the trends of CYP4T in the two groups of crucian carp were considered. The expression levels of CYP4T were higher at $26^{\circ} \mathrm{C}$ when normalized using some reference genes (ACTB, TUBA, G6PDH, ACTB/EEF1A and ACTB/EEF1A/TUBA), and, in contrast, it was lower at $26^{\circ} \mathrm{C}$ when normalized using others (EEF1A, RPL8, GAPDH, B2MG). The ratios of the two groups $\left(26^{\circ} \mathrm{C}\right.$ and $\left.16{ }^{\circ} \mathrm{C}\right)$ were from 0.64 (B2MG) to 2.21-fold (TUBA). No significant effect of these reference 


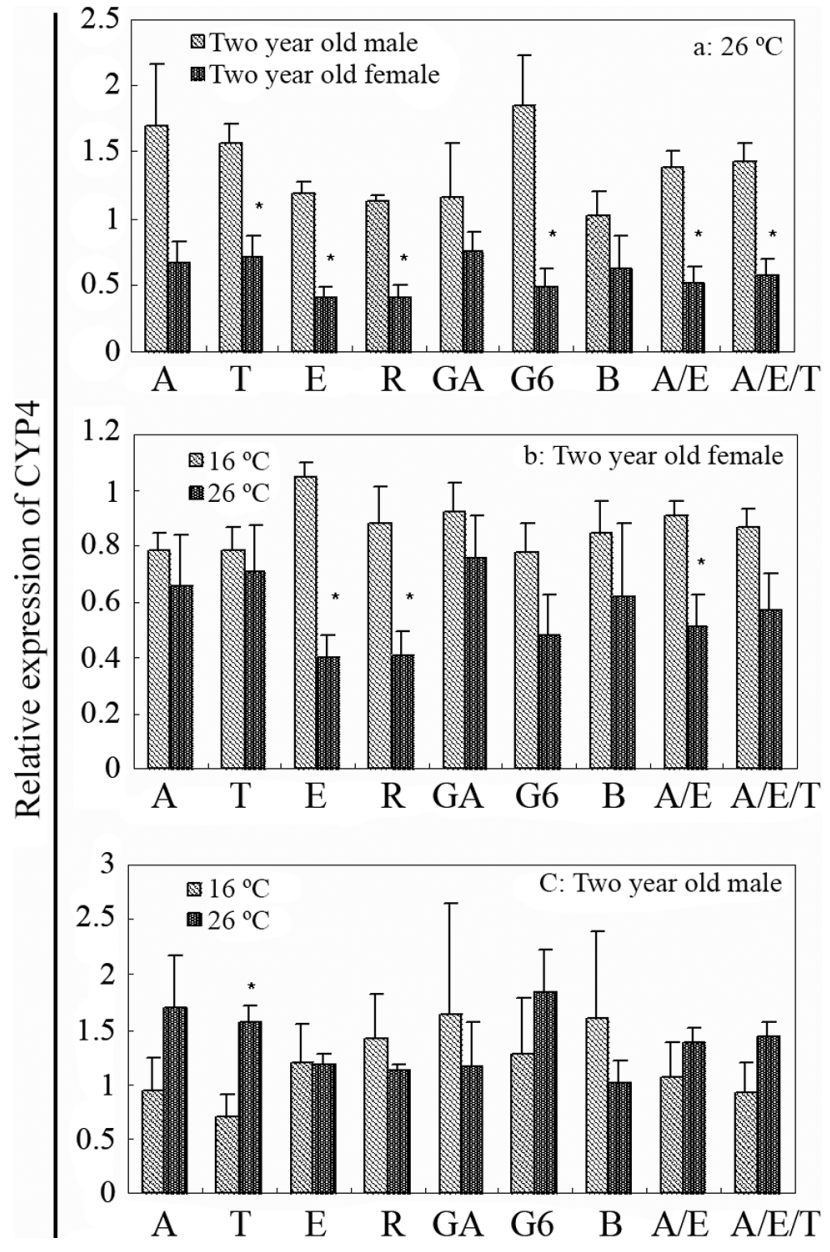

Figure 3 - Expression of CYP4T in the hepatopancreas of crucian carp. Results show the effect of (a) sex on two-year-old fish at $26^{\circ} \mathrm{C}$; (b) different temperature on two-year-old female fish; (c) different temperature on two-year-old male fish. Asterisks $(*)$ indicate significant difference between the two group $(\mathrm{p}<0.05)$. Abbreviations: A - ACTB, T - TUBA, E EEF1A, R - RPL8, GA - GAPDH, G6 - G6PDH, B - B2MG, A/E ACTB/EEF1A, A/E/T - ACTB/EEF1A/TUBA.

genes was observed on the relative gene expression of CYP4T in one-year-old fish and between one-year-old and two-year-old fish (results were not shown).

Based on the above data, the expression levels of CYP4T were more centered after normalizing to the gene combinations, and the combinations also had an effect on the error estimates. These results demonstrate that the relative quantification of target gene expression varied mostly depending on the reference gene and the number of reference genes used for normalization.

\section{Discussion}

The stability and ranking of gene expression in crucian carp were evaluated using GeNorm, Normfinder and Bestkeeper. The three programs all showed consistently that ACTB was the most stably expressed reference gene, whereas G6PDH and B2MG were the least stably ex- pressed genes. Furthermore, GeNorm suggested that the combination of ACTB/EEF1A/TUBA was the most stable one. Normfinder identified ACTB/EEF1A as the most reliable gene-pair. BestKeeper revealed that ACTB and TUBA were the most reliable candidate genes, but EEF1A and RPL 8 could also be used as house keeping genes. However, with a single gene as reference, the calculation of the relative expression level of CYP4T differed (Figure 3), which made it difficult to decide which reference gene should be used to determine if CYP4T expression was closer to truth. The combined normalizing factors inferred by Normfinder and GeNorm indicated that the magnitude of relative expression of CYP4T and the estimation of its error were similar. The combination of two or more reference genes produced more reliable results of the gene expression.

Previous studies demonstrated that reference gene expression could be affected by many factors, such as development, tissue and experimental conditions (Ingerslev et al., 2006; Peters et al., 2007; McCurley and Callard, 2008; Small et al., 2008), and the use of a single reference gene might not produce reliable results for target gene expression (de Jonge et al., 2007; Bustin et al., 2009; Derveaux et al., 2010). It was shown that $25 \%$ of the experiments for quantifying target gene expression using single $v s$. multiple reference genes resulted in a 3.0-fold error, and $10 \%$ with a 6.4-fold error (Vandesompele et al., 2002). Therefore, it is recommended that two or more reference genes and the geometric mean be used to correct the relative expression of the target gene and to improve the reliability of the expression (Nailis et al., 2006; McNeill et al., 2007; PomboSuarez et al., 2008; Wood et al., 2008). However, there is a limit to the number of genes in combination so that an optimal combination of reference genes needs to be identified (Ling and Salvaterra, 2011).

There are a number of programs, such as GeNorm, Bestkeeper and NormFinder used in this study, for evaluating and selecting stable reference genes. Although the algorithms of these software-programs are different, they often produce similar results. However, they may also produce different outcomes, as seen in this study. It remains unknown which program is better for selecting reference genes. Some studies suggest that GeNorm might select reference genes of similar expression by a pairwise approach but the selected genes might not be the most stable genes, and if the expression pattern of candidate reference genes is dissimilar, no genes will meet the stability threshold for including potential stable reference genes (Andersen et al., 2004; Wood et al., 2008). In the present study, GeNorm and NormFinder, applying different methods of calculation, resulted in similar stable reference genes. In addition, both programs suggested to use combinations ofreference genes, and the ranking of the stability of the single reference genes identified by BestKeeper was analogous to that by GeNorm; but BestKeeper did not suggest a suitablegene combination. In the present study, GeNorm and 
Normfinder suggested that the combination of ACTB/EEF1A/TUBA or of ACTB/EEF1A be used to measure the expression of the target gene, since the relative expression of the target gene CYP4T was unstable underour experimental conditions when a single reference gene was used (Figure 3).

\section{Conclusion}

To the best of our knowledge, this is the first study examining the expression of CYP4T in crucian carp and to test the stability of reference genes under such complex conditions. In this study, all the seven reference genes were found to have some degrees of variability under the various conditions (sex, age, water temperature, and drug treatments), and there was no single best gene for the experiments. We recommend using the geometric average of the combination of ACTB/EEF1A or of ACTB/EEF1A/TUBA as a normalization factor for RT-qPCR analysis of gene expression in crucian carp following these and possibly other treatments. These results underlined the importance of validating reference genes prior to use in RT-qPCR, which is of significance studies on fishes.

\section{Acknowledgments}

The research was financially supported by grants from the National Natural Science Foundation of China (Grant No. 090600253). The authors thank Prof. S.L. Huang and Dr. W.L. Li for valuable comments on the manuscript and Prof. F. R. Gu for language editing.

\section{References}

Andersen CL, Jensen JL and Orntoft TF (2004) Normalization of real-time quantitative reverse transcription-PCR data: a model-based variance estimation approach to identify genes suited for normalization. Applied to bladder and colon cancer data sets. Cancer Res 64:5245-5250.

Bustin SA (2002) Quantification of mRNA using real-time reverse transcription PCR (RT-PCR): trends and problems. J Mol Endocrinol 29:23-39.

Bustin SA, Benes V, Garson JA, Hellemans J, Huggett J, Kubista M, Mueller R, Nolan T, Pfaffl MW, Shipley GL et al. (2009) The MIQE guidelines: minimum information for publication of quantitative real-time PCR experiments. Clin Chem 55:611-622.

Chechi K, Gelinas Y, Mathieu P, Deshaies Y and Richard D (2012) Validation of reference genes for the relative quantification of gene expression in human epicardial adipose tissue. PLoS One 7:e32265.

de Jonge HJ, Fehrmann RS, de Bont ES, Hofstra RM, Gerbens F, Kamps WA, de Vries EG, van der Zee AG, te Meerman GJ and ter Elst A (2007) Evidence based selection of housekeeping genes. PLoS One 2:e898.

Derveaux S, Vandesompele J and Hellemans J (2010) How to do successful gene expression analysis using real-time PCR. Methods 50:227-230.
Fathallah-Shaykh HM (2005) Microarrays: applications and pitfalls. Arch Neurol 62:1669-1672.

Filby AL and Tyler CR (2007) Appropriate 'housekeeping' genes for use in expression profiling the effects of environmental estrogens in fish. BMC Mol Biol 8:e10.

Hardwick JP (2008) Cytochrome P450 omega hydroxylase (CYP4) function in fatty acid metabolism and metabolic diseases. Biochem Pharmacol 75:2263-2275.

Ho-pun-Cheung A, Cellier D and Lopez-Crapear-Crapez E (2008) Considerations for normalisation of RT-qPCR in oncology. Ann Biol Clin (Paris) 66:121.

Huggett J, Dhedal K, Bustin S and Zumla A (2005) Real-time RT-PCR normalization; strategies and considerations. Genes Immun 6:279.

Imbeaud S, Graudens E, Boulanger V, Barlet X, Zaborski P, Eveno E, Mueller O, Schroeder A and Auffray C (2005) Towards standardization of RNA quality assessment using user-independent classifiers of microcapillary electrophoresis traces. Nucleic Acids Res 33:56.

Infante C, Matsuoka MP, Asensio E, Cañavate JP, Reith M and Manchado M (2008) Selection of housekeeping genes for gene expression studies in larvae from flatfish using realtime PCR. BMC Mol Biol 9:e28.

Ingerslev HC, Pettersen EF, Jakobsen RA, Petersen CB and Wergeland HI (2006) Expression profiling and validation of reference gene candidates in immune relevant tissues and cells from Atlantic salmon (Salmo salar L). Mol Immunol 43:1194-1201.

Jorgensen SM, Kleveland EJ, Grimholt U and Gjoen T (2006) Validation of reference genes for real-time polymerase chain reaction studies in Atlantic salmon. Mar Biotechnol 8:398-408.

Julin K, Johansena L-H and Sommera A-I (2009) Reference genes evaluated for use in infectious pancreatic necrosis virus real-time RT-qPCR assay applied during different stages of an infection. J Virol Methods 162:30-39.

Lekanne Deprez RH, Fijnvandraat AC, Ruijter JM and Moorman AF (2002) Sensitivity and accuracy of quantitative real-time polymerase chain reaction using SYBR green I depends on cDNA synthesis conditions. Anal Biochem 307:63-69.

Ling D and Salvaterra PM (2011) Robust RT-qPCR data normalization: validation and selection of internal reference genes during post-experimental data analysis. PLoS ONE 6:e17762.

Mackay IM (2004) Real-time PCR in the microbiology laboratory. Clin Microbiol Infect 10:190-212.

McCurley AT and Callard GV (2008) Characterization of housekeeping genes in zebrafish: male-female differences and effects of tissue type, developmental stage and chemical treatment. BMC Mol Biol 9:e102.

McNeill RE, Miller N and Kerin MJ (2007) Evaluation and validation of candidate endogenous control genes for real-time quantitative PCR studies of breast cancer. BMC Mol Biol 8:e107.

Nailis H, Coenye T, Van Nieuwerburgh F, Deforce D and Nelis HJ (2006) Development and evaluation of different normalization strategies for gene expression studies in Candida albicans biofilms by real-lime PCR. BMC Mol Biol 7:2533.

Park WD and Stegall MD (2007) A meta-analysis of kidney microarray datasets: investigation of cytokine gene detec- 
tion and correlation with rt-PCR and detection thresholds. BMC Genomics 8:e88.

Peters IR, Peeters D, Helps CR and Day MJ (2007) Development and application of multiple internal reference (housekeeper) gene assays for accurate normalisation of canine gene expression studies. Vet Immunol Immunopathol 117:55-66.

Pfaffl MW, Tichopad A, Prgomet C and Neuvians TP (2004) Determination of stable housekeeping genes, differentially regulated target genes and sample integrity: BestKeeperExcel-based tool using pair-wise correlations. Biotechnol Lett 26:509-515.

Pombo-Suarez M, Calaza M, Gomez-Reino JJ and Gonzalez A (2008) Reference genes for normalization of gene expression studies in human osteoarthritic articular cartilage. BMC Mol Biol 9:e17.

Rajeevan MS, Ranamukhaarachchi DG, Vernon SD and Unger ER (2001) Use of real-time quantitative PCR to validate the results of cDNA array and differential display PCR technologies. Methods 25:443-451.

Small BC, Murdock CA, Bilodeau-Bourgeois AL, Peterson BC and Waldbieser GC (2008) Stability of reference genes for real-time PCR analyses in channel catfish (Ictalurus punctatus) tissues under varying physiological conditions. Comp Biochem Physiol B Biochem Mol Biol 151:296-304.

Tang R, Dodd A, Lai D, McNabb WC, and Love DR (2007) Validation of zebrafish (Danio rerio) reference genes for quantitative real-time RT-PCR normalization. Acta Biochim Biophys $\operatorname{Sin}$ 39:384-390.
Ullmannova V and Haskovec C (2003) The use of housekeeping genes $(\mathrm{HKG})$ as an internal control for the detection of gene expression by quantitative real-time RT-PCR. Folia Biol 49:211.

Vandesompele J, De Preter K, Pattyn F, Poppe B, Van Roy N, De Paepe A and Speleman F (2002) Accurate normalization of real-time quantitative RT-PCR data by geometric averaging of multiple internal control genes. Genome Biol 3:research 0034.

Wood SH, Clements DN, McEwan NA, Nuttall T and Carter SD (2008) Reference genes for canine skin when using quantitative real-time PCR. Vet Immunol Immunopathol 126:392395.

Zhang Z and Hu J (2007) Development and validation of endogenous reference genes for expression profiling of Medaka (Oryzias latipes) exposed to endocrine disrupting chemicals by quantitative real-rime RT-PCR. Toxicol Sci 95:356-368.

\section{Internet Resources}

Bestkeeper, http://www.wzw.tum.de/genequantification/bestkeeper.html (2010).

GeNorm, http://medgen.ugent.be/ jvdesomp/genorm/ (2010).

Normfinder, http://moma.dk/normfinder-software (2010).

Associate Editor: Igor Schneider

License information: This is an open-access article distributed under the terms of the Creative Commons Attribution License, which permits unrestricted use, distribution, and reproduction in any medium, provided the original work is properly cited. 